\title{
O antissemitismo como ódio obstinado
}

Mariana Rodrigues de Vita* DOI: 10.11606/issn.2318-8855.v10i2p221-236

Resumo: O objetivo desse artigo é historicizar o antissemitismo, ou seja, considerá-lo como objeto de estudo condizente com o tempo em que se insere, levando em consideração as divergências ao longo de sua existência na Europa, as rupturas e continuidades em seu cerne discursivo. Para isso, se faz necessário analisar a vigência do ódio aos judeus em longa duração: desde a Idade Média, sob a ótica da religiosidade e dos moldes de conversão; passando pelo século XIX, em que a raça era vista como característica inerente aos judeus, por isso irreversível; e pelo darwinismo social, presente a partir do fim do século XIX e alinhado às teorias eugenistas. A partir desse panorama contextual, analisamos a documentação primária constituída pelos Protocolos dos Sábios de Sião e pelo Programa de 25 pontos do NSDAP, que foi promulgado pelo Partido Nacional-Socialista dos Trabalhadores Alemães em 1920. A inserção do antissemitismo no núcleo do pensamento coletivo é, de fato, uma construção social, mas se dá simbioticamente ao conjunto das relações sociais, ou seja: trata-se de um axioma, parte significativa e motriz da mentalidade coletiva. $\mathrm{O}$ antissemitismo, portanto, era tão presente que se tornou parte do senso comum e, futuramente, seria a base e justificativa de hediondos crimes contra a humanidade.

Palavras-chaves: Antissemitismo, nazismo, mentalidade coletiva, História Social

* Graduanda de História na Universidade de São Paulo (USP). Faz parte do Projeto Mulheres na América Portuguesa coordenado pelas Professoras Doutoras Maria Clara Paixão de Souza e Vanessa Martins do Monte; e do Grupo de Pesquisa Ana Gertrudes de Jesus, mulher da terra: por uma história social dos grupos subalternos no Sul Global (África \& Américas), coordenado pela Profa ${ }^{\text {. Dra }}{ }^{\text {. }}$ Maria Cristina Wissenbach. E-mail: marianadevita@usp.br 


\section{artigos}

Mariana Rodrigues de Vita

\section{Introdução}

O antissemitismo é comumente relacionado ao nazismo e, principalmente, à figura pessoal de Hitler, já que o ódio fortemente direcionado aos judeus constituía parte significativa da ideologia nazista e foi levado a ultrapassar o limite do imaginável com a criação e utilização de guetos, campos de concentração e campos de extermínio. Porém, assim como a pesquisa acerca da Alemanha nazista não tem como único objeto de análise o Holocausto, o estudo do antissemitismo não se condensa e esgota na Alemanha dos anos 1930 e 1940. É preciso entender a dinâmica e o funcionamento do antissemitismo, considerando a economia, a estratégia militar, os partidos políticos, etc. num período de longa duração.

A agressiva aversão contra os judeus os assola há considerável tempo, e é interessante analisar, a partir da contextualização histórica, como ela se deu em diferentes temporalidades. $\mathrm{O}$ discurso antissemita se manifestava tanto através de ataques violentos que massacravam ou expulsavam essas populações - os chamados pogroms -, como também da visão generalizada dos judeus como estrangeiros, que os impedia de realizar diversas tarefas e poderia levar até à cassação de seus direitos políticos e civis.

A transformação das justificativas dos discursos preconceituosos contra os judeus é um fator de descontinuidade do antissemitismo, não porque este tenha simplesmente deixado de existir em determinados momentos, mas como um elemento de forte integração no seio social, seguindo uma lógica histórica. Primeiramente, no contexto de uma sociedade pautada na religiosidade cristã, o judaísmo era considerado uma religião que não poderia existir simultaneamente ao cristianismo, pois a 


\section{artigos}

\section{O Antissemitismo como ódio obstinado}

raiz comum das duas religiões tornaria seus dogmas excludentes. Seguindo essa concepção, a solução proposta visava à conversão e atacava diretamente a religião em si.

É importante compreender os discursos e as ações subsequentes a ele, pois uma mudança desse paradigma muda também a política de perseguição. A conversão faz sentido dentro do espaço geográfico-temporal da Idade Média Cristã. Contudo, quando o racionalismo e a ciência se tornam fortes, a raça surge como um conceito socialmente construído, entendida como uma característica inescapável do ser, cuja simples existência atua "sujando a raça ariana", e desse modo, a resposta é a eliminação desses sujeitos, vistos antes como objetos e sub-humanos do que como sujeitos, propriamente. Portanto, este artigo se propõe a analisar brevemente o antissemitismo em uma perspectiva de longa duração, estudando duas fontes primárias: os Protocolos dos Sábios de Sião, publicado no início do século XX, e O Programa de 25 pontos do Nationalsozialistische Deutsche Arbeiterpartei (NSDAP), escrito na década de 20, atentando, assim, para a construção imagética e discursiva contra os judeus, elaborada ao longos de várias décadas.

\section{0 antissemitismo pelo viés religioso}

O antissemitismo precisa ser historicizado, visto que sua base explicativa se modifica em diferentes contextos, mesmo que o pressuposto de ódio aos judeus se mantenha fixo. O antissemitismo não deve ser personalizado na figura de Hitler, pois o preconceito já existia muito antes do nascimento político do líder nazista. Entender a trajetória histórica do antissemitismo é importante na concepção do Estado Racial na Alemanha; por mais que o antissemitismo não seja o elemento fundante do nazismo, ele é de fato crucial. (FAUSTO, 1998, p.141) Sendo assim, entendê-lo de forma histórica é, necessariamente, considerar que sua análise passa pela curta duração, 


\section{artigos}

\section{Mariana Rodrigues de Vita}

fixada no período, mas também pela longa duração, analisando o desprezo histórico imposto aos judeus em diferentes períodos.

Remontando à Idade Média, "o anti-semitismo é um corolário da cristandade" (GOLDHAGEN, 1997, p.60). Segundo o autor Daniel Johan Goldhagen, desde os primórdios da consolidação do Império Romano, líderes cristãos já faziam pregações contra judeus. Havia um impasse teológico entre as duas religiões devido à herança em comum com a Bíblia. Para os cristãos, rejeitar os milagres e revelações de Jesus era negar um dos pilares do cristianismo, já que a religião era formada em torno da figura de Jesus Cristo. Portanto, a verdade dos cristãos era posta em xeque com a existência do judaísmo: "ou o Messias era falso, ou essas pessoas haviam se desviado profundamente, talvez tentadas pelo próprio Demônio" (GOLDHAGEN, 1997, p.60)

Sendo assim, o mundo medieval não permitia a coexistência de grupos religiosos que disputavam narrativas, era uma guerra pela verdadeira fé. Essa guerra santa era atroz e assimétrica em seus poderes. Por mais que a Igreja Católica não possuísse poderes ilimitados, era uma instituição influente, enquanto os judeus eram excluídos socialmente. O estudo da iconografia cristã é interessante por mostrar a dimensão da ferocidade contra os judeus; um exemplo é o 'Judensau', que significa 'porca judia', uma obra de arte presente na fachada da Igreja de Santa Maria em Wittenberg, Alemanha. A escultura pejorativa existe desde 1305 e representa judeus sugando as tetas de uma porca, enquanto um rabino segura seu rabo.

Os judeus também não possuíam terras, eram considerados estrangeiros e tinham seu direito de habitação constantemente revogado. (BARON, 1993). Viviam à margem da sociedade, em uma organização coletiva, e quando um indivíduo era assimilado à sociedade ocidental, perdia parte de sua autonomia. 


\section{artigos}

\section{O Antissemitismo como ódio obstinado}

É importante pontuar os diferentes tipos de "soluções" empregadas contra os judeus. A conversão em massa foi um instrumento que almejava o fim do judaísmo como religião. Dentro dessa concepção, "ser judeu" não era uma característica inata do indivíduo, tal como seria entendido e construído posteriormente na ideia de raça.

\section{A construção imagética e discursiva "do judeu" a partir do conceito de raça}

Foi durante o século XIX que se deu a disseminação da eugenia e do darwinismo social, o que, mesmo tendo ocorrido fora da Alemanha, posteriormente influenciaria os nazistas. Em 1859, Charles Darwin publica A Origem das Espécies, seu estudo científico que comprova a seleção natural e evolução das espécies. Segundo ele, ao longo de milhares de anos as espécies poderiam sofrer mutações para melhor se adaptarem ao meio ambiente. Logo após a publicação de Darwin, Francis Galton cunha a ideologia do Darwinismo Social, que pregava a teoria da seleção de raças entre seres humanos. Segundo ele, raças 'inferiores' estariam destinadas a desaparecer. As propostas de Galton são chamadas de "eugenia positiva", pregando o controle reprodutivo que visava o cruzamento apenas de 'raças superiores', diferentemente da "eugenia negativa" que visa à eliminação dos "degenerados".

Nos EUA, a esterilização coercitiva castigou cerca de 70 mil pessoas, e vigorou até 1979, em alguns estados como o da Virgínia. Em uma carta ao biólogo eugenista Charles Davenport, o então presidente Theodore Roosevelt diz que: “Concordo com o senhor se o que quer dizer, como suponho, é que a sociedade não tem porque permitir que os degenerados se reproduzam". (Carta de Theodore Roosevelt ao biólogo eugenista Charles Benedict Davenport, 1913)

O modelo religioso que definia e excluía os judeus foi progressivamente perdendo espaço. A partir do século XIX, emrgiu um novo conceito fixado à definição de 


\section{artigos}

\section{Mariana Rodrigues de Vita}

judeu: a raça. Um fator comum inescapável, uma característica inerente que não poderia ser convertida ou mudada. A noção essencialista de raça pressupunha que o judeu jamais poderia se tornar alemão. (GOLDAHAGEN, 1997, p.77)

O antissemitismo ao longo do século XIX é um objeto de estudos sobre o qual há divergentes perspectivas. Segundo Richard J.Evans, os judeus eram uma minoria de $1 \%$ que se firmava em bairros próprios e que, ao longo do século, foi assimilada à sociedade alemã. Muitas normas contra os judeus foram removidas, como a restrição do casamento entre judeus cristãos. O antissemitismo, segundo Evans, estava presente em pequenos setores representados por 'agitadores', mas não era parte do senso comum. (EVANS,2014, p.55).

Já para Daniel Goldhagen, a mentalidade eliminacionista tendia ao extermínio já desde o século XVIII (GOLDHAGEN, 1997, p.83). Durante o período nazista, o ódio aos judeus fazia parte da mentalidade coletiva social como um axioma, e a mentalidade eliminacionista se alojara na sociedade alemã (GOLDHAGEN, 1997, p.103).

O teor religioso que o antissemitismo tinha na Idade Média recebera uma base moderna, a pseudociência. E o objetivo ou "solução" do antissemitismo em relação aos judeus também mudou de conversão e supressão do judaísmo para o extermínio dos próprios judeus. Se antes havia um contraste entre judeus e cristãos, agora havia um entre judeus e alemães.

\footnotetext{
“O modelo cultural alemão subjacente sobre 'o judeu' (der Jude) era composto por três noções: o judeu era diferente do alemão, estava em oposição binária em relação ao alemão e não era benignamente diferente, mas malevolente e corrosivo. Fossem os judeus tomados enquanto uma religião, nação, grupo político ou raça, eram sempre um FremdkrOper, um corpo estranho na Alemanha. (GOLDHAGEN, 1997, p.66)
} 


\section{artigos}

\section{O Antissemitismo como ódio obstinado}

O antissemitismo era, em si mesmo, destrutivo: "não se trata de construir uma sociedade, mas apenas de purificar a já existente" (SARTRE, 1995: 29-30). Viver enquanto judeu foi reavaliado pela ciência da raça, que os diminuiu a um estrito destino biológico (FUKS, 2011, p.387). "O judeu” era um corpo estranho na sociedade alemã, coisificado como um personagem monolítico com características generalizadas que supostamente representariam os judeus como um todo. E nenhuma característica real do objeto, que é a fonte do preconceito, explica o ódio e a aversão (GOLDHAGEN, 1997, p.5). Segundo Sartre, o antissemitismo é uma escolha, e não um fator externo, é uma fé que desvaloriza a razão em prol da própria reafirmação, pois ao afirmar que o judeu é inferior, o sujeito preconceituoso se afirma como superior. (SCHMIDT, 2005, p.5)

\section{A invenção da periculosidade como vetor da diferença}

Os judeus eram vistos como extremamente perigosos e nocivos à sociedade, com poderes de atuação e destruição tão irreais que chegavam a parecer sobrenaturais. Eram considerados destruidores, e a retórica poderia fazê-los ser tanto banqueiros implacáveis, quanto bolcheviques. Houve uma mudança linguística e cognitiva na imagem do judeu, iniciada em meados do século XIX. (GOLDHAGEN, 1997, pp.65). Um documento relevante para o entendimento da narrativa do "domínio total" dos judeus perante o mundo é "Os Protocolos dos Sábios de Sião", um documento forjado e supostamente criado por Mathieu Golovinski, em 1898, no qual líderes judeus se reúnem para discutir a dominação mundial:

Quando for necessário reforçar as medidas de proteção policial, que arruínam tão rapidamente o prestígio do poder simularemos desordens, manifestações de descontentamento expressas por bons oradores. Juntar-se-ão a eles pessoas que alimentem os mesmos sentimentos. Isto nos servirá de pretexto para autorizar buscas e vigilâncias, cujos agentes serão os servidores que 


\section{artigos}

Mariana Rodrigues de Vita

tivermos no seio da polícia dos cristãos. (Os protocolos dos Sábios de Sião, 1991, p.72)

Nesse excerto, é possível identificar uma retórica que almeja propositadamente o caos e a destruição da sociedade cristã, através de um planejamento vil e ardiloso. O exagero em colocar um seleto e pequeno grupo de pessoas com poder de mudar tão rapidamente e de forma radical o mundo ao seu bem entender é uma forma de criar medo e semear a ideia de periculosidade dos judeus.

O documento falsificado e publicado nos primórdios do século XX foi resultado de um considerável plágio do Diálogo no Inferno Entre Maquiavel e Montesquieu, publicado em 1865 por Maurice Joly (VIERA, 2019, p.7). O texto emula atas de uma suposta conferência internacional com poderosos judeus que iriam maquinar contra todas as instituições vigentes. E esses ares de super-poderes dos judeus alinham-se à forma diabólica com a qual, alegadamente, eles causariam a arruinação da sociedade, com uma busca desenfreada pelo poder que se daria pelas entranhas dos próprios sistemas político e econômico de cada país. A publicação, que faz parte de uma teoria da conspiração sobre a dominação do mundo pelos judeus, seria parte relevante da justificativa para a perseguição contra eles, tornando-se, posteriormente, uma das obras antissemitas mais difundidas.

\section{A edificação do Estado racial sob a égide da institucionalização do antissemitis- mo}

A questão eliminacionista na Alemanha do século XX era um produto lógico da ideia de judenrein, e o debate residia em como colocar a política de morte em prática (GOLDHAGEN, 1997, p.93). O genocídio foi a insitucionalizado. O assassinato em massa foi não só uma possibilidade posta, mas, de fato, uma política executada, fruto de 


\section{artigos}

\section{O Antissemitismo como ódio obstinado}

um ódio crônico e da incapacidade de enxergar o Outro como semelhante. (EHRILICH, 2016, p.84). Para Hannah Arendt, a mediocridade se aproxima dessa falta de compaixão com outro ser humano, uma ausência vista em Eichmann, um homem condenado pelo Tribunal de Nuremberg por sua participação crucial na logística mortífera do Holocausto. A filósofa debatia que o obscurantismo do nazismo vem do fato que ele não é formado por homens diferentes do comum, por monstros, mas sim por seres humanos que se recusam a pensar, em uma irracionalidade que não vem da ignorância, mas da abjeção pelo próprio ato de pensar:

“E os juízes não acreditaram nele, porque eram bons demais e talvez também conscientes demais das bases de sua profissão para chegar a admitir que uma pessoa mediana, "normal", nem burra, nem doutrinada, nem cínica, pudesse ser inteiramente incapaz de distinguir o certo do errado. Eles preferiram tirar das eventuais mentiras a conclusão de que ele era um mentiroso - e deixaram passar o maior desafio moral e mesmo legal de todo o processo. A acusação tinha por base a premissa de que o acusado, como toda "pessoa normal", devia ter consciência da natureza de seus atos, e Eichmann era efetivamente normal na medida em que "não era uma exceção dentro do regime "nazista". No entanto, nas condições do Terceiro Reich, só se podia esperar que apenas as "exceções" agissem "normalmente". (ARENDT, 1999, p.20)

Um documento emblemático e representativo da ascensão do nazismo como um todo, mas também do antissemitismo, é o Programa de 25 pontos do Nationalsozialistische Deutsche Arbeiterpartei (NSDAP) que foi promulgado pelo Partido NacionalSocialista dos Trabalhadores Alemães em 1920, escrito por Hitler e Anton Drexler, fundador do partido. O documento jamais seria alterado e, em sua essência, continha frases sintéticas e propagandísticas da ideologia nazista. O item número 4 dizia que:

\footnotetext{
"Apenas um membro da raça pode ser um cidadão. Um membro da raça só pode ser aquele que é de sangue alemão, sem consideração de credo. Consequentemente nenhum judeu pode ser um membro da raça." (Programa de 25 pontos do NSDAP, 1920) ${ }^{1}$
}

\footnotetext{
1 "Only a member of the race can be a citizen. A member of the race can only be one who is of German blood, without consideration of creed. Consequently no Jew can be a member of the race." (25-point
} 


\section{artigos}

Mariana Rodrigues de Vita

O Programa era uma síntese do Estado racial nacionalista e antissemtia, no qual a validação de pertença era baseada em critérios de raça. Eram considerados cidadãos apenas os não judeus, como foi destacado no ponto 4, sendo eles os únicos com direitos civis e administrativos, como é reforçado no ponto número 9, que diz que todos os cidadãos devem ter igualdade de direitos.

É interessante pontuar que um cidadão era tido como tal devido a sua linhagem alemã, independente do credo. O ponto 24 do Programa até defendia liberdade de religião, "desde que não ponham em perigo a sua existência ou se opor aos sentidos morais da raça germânicas" (Programa de 25 pontos do NSDAP, 1920). Sendo assim, um judeu nunca poderia ser considerado um alemão. Os judeus que se consideravam primeiro alemães, e depois judeus, e até lutaram pela Alemanha durante a Primeira Guerra Mundial, receberam uma narrativa desqualificadora: os traídos que levaram a Alemanha à queda e à vergonha.

Os sentimentos de humilhação e constrangimento coletivos seriam cruciais no pós-guerra. O nazismo utilizara o antissemitismo como uma política chave de união nacional e reafirmação em um período obscuro de forte crise econômica (Cytrynowiczp, 1990, p.24). Quinze anos após a promulgação do Programa de 25 pontos da NSDAP, o nazismo já havia se infiltrado no poder pelas vias legais. Em 1935, as Leis de Nuremberg - entre elas a "Lei para Defesa do Sangue e da Honra" - pretendiam levar a justiça social ao seu povo através da legislação, criminalizando relações interpessoais ou sexuais entre judeus e alemães: “Para justiça alemã, cometer um 'crime racial' era pior que homicídio (...)" (Cytrynowiczp, 1990, p.17).

\footnotetext{
Program of the Nazi Party)
} 


\section{artigos}

\section{O Antissemitismo como ódio obstinado}

Os indivíduos que contrariavam a inércia e a lógica antissemita representavam uma parcela minoritária das populações solapadas pelo nazismo, chamados de 'justos entre as nações', apesar de esta não ser uma categoria uniforme. A comissão do Yad Vashem aceitou oficialmente mais de 26 mil pessoas dentro desse parâmetro. São indivíduos que não só discordaram da ideologia, mas praticaram atos benignos em prol dos judeus, escondendo-os, ajudando-os a migrar, etc, ou seja, salvando-os de alguma maneira e, assim, correndo sérios riscos contra a sua própria integridade física e a de suas famílias. Em um contexto de regime totalitário, no qual o espaço público é exterminado e o Estado se pretende presente em todas as entranhas da sociedade, qualquer ato de discordância é um ato político. (EHRILICH, 2016, p.80)

Por fim, o que acometera a Alemanha, mas também a Europa como um todo, foram os campos de concentração e extermínio. Para Primo Levi, “O mundo no qual se precipitava era decerto terrível, mas também indecifrável". (LEVI, 2016, p.28). Definitivamente algo de novo manchara a humanidade. Michael Löwy conceitualiza os genocídios do século em questão como "barbárie civilizada", que moderniza as tecnologias em prol de uma política genocida. Segundo Löwy, a modernidade do século XX foi berço de um fenômeno completamente novo em sua essência. Massacres e genocídios já haviam ocorrido em diversos episódios de diferentes lugares do mundo, mas a "barbárie civilizada" se explica por quatro elementos principais: a industrialização do homicídio, sintetizada pelas câmaras de gás; a impessoalidade do massacre, que aniquila a individualidade e humanidade dos judeus; a gestão burocrática, na qual se incorporam a logística do funcionamento dos campos, como a questão do transporte; e por último, a ideologia legitimadora do tipo moderna, que não mais se baseia na religiosidade, mas no aspecto biológico e científico com teor higiênico. (LOWY, 2010, p.9) 


\section{artigos}

Mariana Rodrigues de Vita

\section{Conclusão}

O antissemitismo, portanto, vincula-se ao nazismo de maneira simbiótica e é essencial para entendê-lo, mas não se limita a esse período histórico. Sua longa duração é reveladora quanto ao porquê de serem os judeus o povo marcado para a perseguição e o massacre, ou seja, eles não foram "escolhidos aleatoriamente": historicamente, os judeus foram perseguidos e hostilizados. Durante o século XIX, houve uma mudança de paradigma no princípio transmutado da ordem religiosa para a racial. O antissemitismo era uma presença constante na cultura alemã do século XX, e foi um ódio progressivamente direcionado para a ascensão do Estado racial nazista.

Nesse sentido, a análise dos documentos Os Protocolos dos Sábios de Sião e O Programa de 25 pontos do Partido Nazista é interessante quando feita e contextualizada na longa duração, dimensionando o cárater histórico da perseguição aos judeus - O primeiro documento é parte de uma teoria da conspiração, logo, um documento que forjava um encontro entre judeus para a coordenação e dominação do mundo cristão, sendo esta uma narrativa que tenta justificar e incitar a perseguição aos judeus. Já o segundo é constituído por tópicos de caráter normativo sobre o esperado Terceiro Reich, na qual a exclusão dos judeus seria de fato efetivada.

Em ambas as fontes, o ódio aos judeus é explícito e direto, colocando-os como perigosos para a sociedade, e os Protocolos dos Sábios de Sião seriam utilizados justamente para transmitir para a sociedade essa mensagem. Os documentos estão situados dentro da lógica moderna da diferença de raça, sendo assim, a marginalização era considerada essencial para o "espaço vital" e "bem-estar" social, como foi dissertado em vários tópicos do Programa de 25 pontos. Além disso, há uma forte ligação 


\section{artigos}

\section{O Antissemitismo como ódio obstinado}

entre ambos, já que os Protocolos foram usados como arma publicitária por Adolf Hitler, que foi um dos escritores do Programa do partido nazista.

O ódio aos judeus foi, portanto, um senso comum dentro da sociedade nazista e apenas poucos indivíduos não compactuavam com essa ideologia. Por mais que a resistência fosse quase impossível, o autor Daniel Goldhagen demonstra, a partir de análises documentais e revisão da literatura acadêmica, que o antissemitismo era praticamente um fato inescapável na Alemanha nazista, ou seja, fazia parte da mentalidade coletiva e estava impregnado em toda sociedade.

Uma perseguição dessa magnitude, que promulgou Leis, institucionalizou o ódio a determinados grupos e terminou com o extermínio industrial de seis milhões de vidas, das mais jovens até as mais velhas, está para muito além de um homem só, como Eichmann, foi um sistema voltado para matar. Tendo isso em vista, é interessante a perspectiva, trazida por Daniel Goldhagen, de que esse genocídio, de certo modo, esteve presente em ideologia, cumplicidade ou condescendência na população alemã de modo geral. O antissemitismo estava profundamente entrenhado na sociedade há algum tempo, pressionando vividamente os judeus a migrar e a fazer trabaIhos considerados menos dignos. A visão pejorativa em relação a eles retirava uma parcela da sua humanidade e compaixão, na visão dos não-judeus.

Existem outras correntes de pensamento que não vinculam tão diretamente a sociedade e o antissemitismo de forma constante e marcantemente presente, considerando que houve hiatos da manifestação do ódio. No entanto, se o antissemitismo for analisado em longa duração e se for considerado como um axioma social, a concepção de que o ódio foi silenciado ou superado em determinados períodos e a ideia de desconhecimento e concordância da sociedade são questionáveis. 


\section{artigos}

Mariana Rodrigues de Vita

De fato, é difícil compreender e saber o limite dessa anuência, se a maioria da população apoiava os métodos ou não. O que podemos apreender é que o antissemitismo foi historicamente persistente, transmutou o discurso conforme o contexto em que se inseria, mas não deixou de existir e seduzir os que se consideravam melhores que o mediano ao dizer explicitamente que há seres humanos superiores e inferiores. Há um considerável esforço de historiadores, museólogos, sobreviventes dos campos, líderes religiosos e muitos outros, em reunir e contar exaustivamente histórias que reafirmam e gritam o horror do Holocausto a partir do lema "Não esquecer, não repetir", ultrapassando as próprias dores para contar mais uma vez ao mundo o que foi um dos episódios mais vergonhosos e sinistros da nossa história.

O antissemitismo, no entanto, ainda não foi completamente superado no presente, e não cessou após o término da guerra. Sendo assim, estudos que focam na investigação da perseguição aos judeus e do Holocausto são deveras importante para que os discursos dos perpetradores não sejam hegemônicos, e que a ironia dos soldados da SS não seja tragicamente profética: "Seja qual for o fim dessa guerra, a guerra contra vocês nós ganhamos (...) o mundo não lhe dará crédito. (LEVl, 2016, p.9).

\section{Fontes}

"Justiça Alemã decide que arte antissemita pode permanecer em igreja", Terra, 4 de fevereiro de 2020. Disponível em: https://www.terra.com.br/noticias/justica-alemadecide-que-arte-antissemita-pode-permanecer-emigreja,ed7020d2f0b150ea92e846f191c79413abivucip.html Acessado em: 23/11/2020 às $22 \mathrm{~h} 17$ 


\section{artigos}

O Antissemitismo como ódio obstinado

JACKSON, Steven. LANG-STANTON, Peter. Eugenia: como movimento para criar seres humanos 'melhores' nos EUA influenciou Hitler. Disponível em: https://www.bbc.com/portuguese/internacional-39625619

O "Caso Dreyfus": no dia 12 de julho de 2006, a França celebrou 100 anos da reabilitação do capitão Alfred Dreyfus. O jovem oficial judeu foi protagonista do infame e mundialmente conhecido "caso Dreyfus". (...) Morashá (54) setembro de 2006. Disponível em: http://www.morasha.com.br/antissemitismo/o-casodreyfuss.html

LEVI, P. Assim foi Auschwitz: testemunhos 1945-1986. Companhia das Letras, 2015.

LEVI, P. Os afogados e os sobreviventes: os delitos, os castigos, as penas, as impunidades. Paz\&Terra. Rio de Janeiro, 2016.

\section{Referências}

ARENDT, H. Prefácio à terceira parte: o totalitarismo. In: ARENDT, H. O Sistema totalitário. Lisboa: Edições Dom Quixote, 1973.

ARENDT, Hannah. Origens do Totalitarismo. São Paulo: Companhia das Letras, 2012.

ARENDT, H. Eichmann em Jerusalém. Companhia das Letras: São Paulo, 1999.

BARON, S. "Nuevos enfoques acerda de la emancioación judia” In: BANKIER, D. (ed) La emancipacíon judía: antologia de artículos en perspectiva histórica. Jerusalém: Publicaciones Monte Scopus, 1983. pp.238-266

CYTRYNOWICZ, R. Memória da Barbárie: a história do genocídio dos judeus na segunda guerra mundial. Nova Stella: Editora da Universidade de São Paulo, 1990.

EHRILICH, M. "A compaixão na política - o caso dos justos entre as nações". Revista eletrônica discente história.com, Bahia, v.3, n.6, 2016. pp.78-94

EVANS, R. A chegada do Terceiro Reich. São Paulo: Planeta, 2014.

FAUSTO, B. Ensaio bibliográfico: a interpretação do nazismo, na visão de Norbert Elias. MANA 4(1):141-152, 1998.

FUKS, B. A propósito da obra Retorno à questão judaica: diálogo com Elisabeth Roudinesco. Rev. Latinoam. Psicopat. Fund., São Paulo, v.14, n.2, junho de 2011. pp.383-389 


\section{artigos}

Mariana Rodrigues de Vita

GUERRA, Andre. Do holocausto nazista à nova eugenia no século XXI. Cienc. Cult. V (58), n(1). São Paulo: Jan./Mar 2006.

GOLDHAGEN, Daniel. Os carrascos voluntários de Hitler: o povo alemão e o holocausto. São Paulo: Companhia das Letras, 1997.

LOWY, M. “Barbárie e modernidade no século 20". Tradução de Alessandra Ceregatti, Acessado em: https://www.ecodebate.com.br/2010/05/20/barbaire-e-modernidadeno-seculo-20-artigo-de-michael-lowy/ Acessado em:_23/11/2020 às 22:13

SNYDER, T. Terra Negra: O Holocausto como história e advertência. São Paulo: Companhia das Letras, 2015.

SCHMIDT, Maria Luiza. Sartre e a questão do preconceito. Imaginario. v.11 São Paulo dez. 2005.

VIEIRA, Fábio Antunes. O antissemitismo em uma breve perspectiva histórica: de Roma ao nazismo. Arquivo Maaravi: Revista Digital de Estudos Judaicos da UFMG. Belo Horizonte, v. 13, n. 25, nov. 2019. 